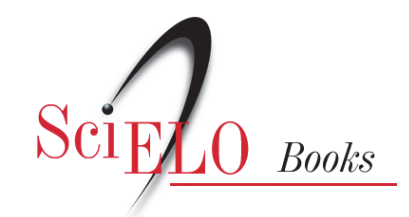

\title{
Gênero, educação e história
}

Deficiência e maternidade: uma análise feminista na APAE-CG

\author{
Antônio Roberto Seixas da Cruz
}

\section{SciELO Books / SciELO Livros / SciELO Libros}

MACHADO, CJS., SANTIAGO, IMFL., and NUNES, MLS., orgs. Gêneros e práticas culturais: desafios históricos e saberes interdisciplinares [online]. Campina Grande: EDUEPB, 2010. 256 p.

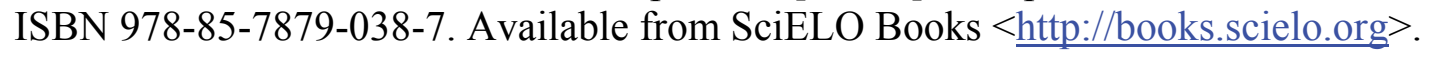

\section{(1)(1)(2)}

All the contents of this work, except where otherwise noted, is licensed under a Creative Commons Attribution-Non Commercial-ShareAlike 3.0 Unported.

Todo o conteúdo deste trabalho, exceto quando houver ressalva, é publicado sob a licença Creative Commons Atribuição Uso Não Comercial - Partilha nos Mesmos Termos 3.0 Não adaptada.

Todo el contenido de esta obra, excepto donde se indique lo contrario, está bajo licencia de la licencia Creative Commons Reconocimento-NoComercial-CompartirIgual 3.0 Unported. 


\title{
Deficiência e maternidade: uma análise feminista na APAE-CG
}

\author{
Lígia Pereira dos Santos
}

Neste artigo, privilegiamos estudar as percepções e ações no exercício da maternidade, destacando os condicionantes de gênero e os mitos construídos que influenciam na caracterização e no comportamento das mulheres-mães com filhos e/ou filhas com deficiência que são usuários/as da APAE-CG.

A pesquisa faz parte de um projeto de Iniciação Científica-PIBIC ${ }^{1}$, da Universidade Estadual da Paraíba, sob a orientação da autora, confere atenção especial à construção social da maternidade e às características que o sentimento materno de mães de pessoas com deficiências assumem na sociedade contemporânea.

Nesta investigação, debatemos a respeito da invisibilidade do trabalho de mulheres-mães que geraram filhos/as com deficiência, isto é, discutimos o trabalho reprodutivo realizado no âmbito privado e correlato à escolaridade, que não chega a ser classificado como uma atividade produtora de riqueza. Afazeres domésticos, cuidado escolares com filhos e filhas e com a família em geral, são atividades domésticas específicas da maternidade e feminilidade, portanto caracterizadas como trabalhos de mulher, nunca como trabalho.

1 A pesquisa tem como bolsista pesquisadora a aluna de graduação Valmira Lúcia Matias Felipe. 
Caminhamos na proposta teórica metodológico da micro-história (VAINFAS, 2002) como um instrumento de construção do conhecimento, interessante do ponto de vista ético dos relatos de minorias, além de ser um instrumento privilegiado para relato do cotidiano das mulheres-mães das pessoas com deficiência.

Analisamos, à luz do paradigma feminista (BADINTER, 1993; FORNA, 1999; SCOTT, 1995), as construções das relações de gênero no cotidiano da educação de pessoas com deficiência, articuladas a estruturas de desigualdade social familiar e docente em diversos contextos, tais como: atividades escolares cotidianas, reuniões de pais-mães e mestras/es, e em momentos festivos.

A pesquisa mostra que, para além trabalho de produção de bens, coisas ou mercadorias, existe o trabalho de manutenção da vida e reprodução das pessoas, que constitui uma grande parte daquele realizado pelas mulheres-mães- o chamado trabalho na reprodução social ou trabalho reprodutivo, geralmente invisível.

O debate feminista revela que, não fosse o trabalho doméstico realizado no cotidiano pelas mulheres, não haveria força de trabalho masculina disponível para movimentar as máquinas das fábricas, o comércio, as obras arquitetônicas, etc. Imaginemos o que aconteceria com o mundo se as mulheres fizessem uma greve de trabalho doméstico, e se as mulheres-mães também o fizessem do exercício da maternidade?

\section{Refletindo historicamente sobre a condição feminina}

Os modelos sociais da construção social e das modificações pelas quais a família tem passado permitiram a organização moderna de Estado e acompanharam a instalação da ordem econômica, social e sexual em diferentes momentos da história da humanidade.

A história da humanidade revela que foram delegadas às mulheres tarefas consideradas aptas à sua feminilidade e que se aproximavam, na verdade, das arefas domésticas e das construções culturais de gênero sobre o significado da diferença entre feminino e masculino.

Se olharmos, por exemplo, a história da arte desde a Antiguidade, observase figuras e imagens de variadas obras-de-arte que retrataram a vida familiar. 
Encontramos sempre mulheres trabalhando, nas suas residências - que era considerado o seu espaço apropriado - cuidando da casa, zelando pela família, cuidando dos filhos e filhas, cozendo, costurando, lavando roupas, fazendo remédios, ajudando na comunidade. Os trabalhos manuais, que exigiam destreza, eram considerados "femininos". Assim, as mulheres se construíram como as principais trabalhadoras domésticas, em atividades manuais e artesanais, alicerçando, assim, uma das vertentes da violência simbólica² ${ }^{2}$ (BOURDIEU, 2003).

Os trabalhos da maternidade realizados, há muitos séculos pelas mulheres, também são desconsiderados, cuja contribuição nunca é valorizada, visto que atividades domésticas como: preparo de alimentos, cuidado com saúde, higiene do corpo, limpeza do ambiente doméstico, zelo com a família representam responsabilidade praticamente exclusiva das mulheres na maioria das sociedades.

A divisão, que é socialmente construída, segrega atividades entre homens e mulheres e atribui um menor valor ao trabalho realizado pelas mulheres.

A ideia de divisão internacional do trabalho, isto é, a barreira entre países ricos e pobres; e o conceito de divisão social e técnica do trabalho, isto é, a divisão entre aqueles que exploram a força de trabalho de homens e mulheres e estes homens e mulheres que vendem sua força de trabalho para sobreviver, são centrais. A estas divisões soma-se a divisão do trabalho entre os sexos, que classifica algumas atividades como masculinas e outras como femininas.

A força da ordem masculina se evidencia no fato de que ela dispensa justificação: a visão androcêntrica impõe-se como neutra e não tem necessidade de se enunciar em discursos que visem a legitimá-la. A ordem social funciona como uma imensa máquina simbólica que tende a ratificar a dominação masculina sobre a qual se alicerça: é a divisão do trabalho, distribuição bastante estrita das atividades atribuídas a cada um dos dois sexos, de seu local, seu momento, seus instrumentos; é a estrutura do espaço, opondo o lugar de assembléia ou de mercado, reservados aos homens, e a casa, reservada às mulheres; (BOURDIEU, 2003, p. 18).

A divisão sexual do trabalho acontece de maneira bastante injusta e desigual. Refletindo assim, percebemos que o trabalho doméstico realizado pelas

2 A violência simbólica refere-se a toda ação ou omissão que prejudique o bem-estar, a integridade física, psicológica ou a liberdade e o direito ao pleno desenvolvimento de qualquer membro da família, que assume a função parental, ainda que sem laços de sangue, como padrastos, madrastas, sogros, sogras, entre outras. 
mulheres-mães de crianças sem deficiências historicamente em diferentes sociedades tem sido invisível e desvalorizado e, muitas vezes, sequer considerado como atividade econômica.

A realidade nos faz testemunhar mudanças profundas nas relações parentais da família contemporânea. Somamos às instabilidades acima referenciadas as especulações sobre a atual insegurança masculina diante da mulher independente profissionalmente.

O debate do papel da mulher trabalhadora no cuidado com os filhos/ as, (FORNA, 1999), tornou-se central na atualidade. É inegável que há uma relevante sobrecarga de atividades para mulher no espaço público e privado, gerando um mal-estar, que entra em contradição com as atividades das mulheres, que já não aceitam pacificamente a chamada determinação biológica para a maternidade.

A proposta feminista questiona os valores tradicionais, impondo uma reavaliação da noção de maternidade e paternidade. É evidente que as pesquisas em Ciências Humanas e Sociais e as ações políticas têm relacionado o conceito de homem ao genérico ser humano e o conceito de gênero às mulheres. Seja na posição de universal (homem = ser humano), seja nos estudos de gênero, "a masculinidade hegemônica é um modelo cultural ideal - não é, portanto, atingível por praticamente nenhum homem” (CONNEL, 1995, p. 189).

No ocidente, principalmente, após a Segunda Guerra Mundial, o papel social da mulher foi associado à maternidade, sendo ela vista como reprodutora e cuidadora que tinha como dever de cuidar e zelar pela casa, pelo marido e pelo/a/s filho/s/as, alimentando, protegendo e higienizando. Note-se que o modelo socialmente definido para a mulher, especificamente, a partir do século XVIII e principalmente no século XIX, desenhou uma nova imagem de sua relação com a maternidade, segundo a qual o bebê e a criança transformaramse nos objetos privilegiados da atenção materna.

Articulando-se aos interesses econômicos do Estado, discursos proferidos por médicos, moralistas e intelectuais reforçavam a necessidade de a mulher ocupar-se com os filhos e as filhas. Tal discurso baseava-se, principalmente, no argumento de que essa seria a forma "natural" de cuidados com a criança e, por isso, a mais adequada; uma vez que só a mulher era capaz de gestar e 
parir, seriam, pois, concernentes, apenas, à "natureza feminina", a educação e os cuidados com a prole.

A “devoção e presença vigilante da mãe" surgem como valores essenciais, sem os quais os cuidados necessários à preservação da vida da criança estariam fadados ao fracasso. A ampliação das responsabilidades maternas fez-se acompanhar, portanto, de uma crescente valorização à "rainha do lar". O gênero se constitui pela linguagem, ou seja, pelo discurso, "o discurso é um instrumento de orientação do mundo, mesmo se não é anterior à orientação da diferença sexual" (SCOTT, 1995, p. 90).

O paradigma feminista almeja desconstruir os estereótipos femininos e a ideia de que a mulher frágil por natureza nasceu para ser mãe e vivenciar o amor materno, devendo cuidar do/a filho/a, a vida inteira, considerando que esse tipo de amor é tido como incondicional e instintivo. Assim, neste sentido, comungamos com a ideia de que:

O amor materno é infinitamente complexo e imperfeito. Longe de ser um instinto, ele é condicionado por tantos fatores independentes da "boa natureza" ou da "boa vontade" da mãe que é preciso um pequeno milagre para que este amor seja assim como é descrito. Ele depende não só da história pessoal de cada mulher (pode-se ser uma mãe má ou medíocre de geração a geração), da convivência da gravidez, de seu desejo de ter a criança, de sua relação com o pai, mas também de outros fatores, sociais, culturais, profissionais etc (BADINTER, 1993, p.67).

O modelo de maternidade tal qual vemos hoje foi mudando de acordo com o tempo, influenciado por diversos campos da ciência, dentre eles destacamos a Psicologia e o Direito.

A Psicologia pelo fato de afirmar que o contato do/a filho/a com a mãe é de extrema importância para o bom desenvolvimento da criança. Caso a mãe "se atreva" a se ausentar na vida cotidiana do/a filho/a, ela passa a ser acusada de causadora dos problemas futuros que ele/a possa vir a apresentar.

O Direito pelo fato das leis até pouco tempo estabelecerem que a custódia dos/as filhos/as seria dada à mãe no caso de separação, embora na atualidade, tenha sido aprovada a lei estabelecendo a guarda dos/as filhos/as compartilhada entre pais e mães, forçando à paternidade responsável. 
[...] foi assim que a maternidade se tornou o que é hoje: um dos estados humanos mais naturais, e um dos mais policiados, uma responsabilidade única da mulher, não apenas um dever, mas uma vocação altamente idealizada, cercada de emoção por todos os lados (FORNA, 1999, p.55).

A partir da década de 1980, o movimento feminista integra na sua luta o reconhecimento e a defesa da diferença entre homens e mulheres. Ao lado da igualdade de acesso ao poder, propõe o valor da diferença pela busca de uma outra "ética", de uma busca ou reconhecimento de outro "modo" ou "estilo" de exercer o poder e de estabelecer relações solidárias, de construir um perfil emocional específico nas relações familiares.

A presença feminina torna-se maciça em todos os movimentos de luta, quer sejam eles sociais e/ou políticos. As identidades femininas e masculinas se constroem, articulando criativamente e/ou contraditoriamente a relação entre igualdade e diferença.

\section{Refletindo sobre a realidade}

Os resultados da pesquisa realizada na APAE-CG com universo de 100 entrevistados/as, dos quais, selecionamos 29 mulheres para ser amostra, revela uma necessidade de intervenção educacional nos valores sobre paternidade e maternidade no seio das relações de pessoas com deficiências.

Utilizamos nomes de plantas para identificar as mães pesquisadas, por entender que ao dedicarem suas vidas (sem partilha nas atividades) no cuidado dos/as seus/as filhos/as deficientes, essas mulheres acabam se tornando como plantas, fixas e quase imóveis, dando sombra e alimento aos/as que necessitam da sua proteção.

Os pseudônimos escolhidos pelas próprias mães foram: Cajueiro, Macieira, Cumaru, Jaqueira, Coqueiro, Quixabeira, Bananeira, Umburana, Ipê Amarelo, Mangueira, Umbuzeiro, Jara, Tamareira, Ingazeira, Velame, Mororó, Facheiro, Macambira, Mariporanga, Catingueira, Palma, Jenipapo, Trapiá, Jurema-Branca, Carnaúba, Maniçoba, Mofumba, Louro, Cardeiro, Marizeiro. Pretendemos, com a utilização desses pseudônimos, preservar a identidade das mesmas. 
Podemos observar que no universo de 100 pessoas acompanhantes entrevistadas $88 \%$ mães, $6 \%$ são avós e tias, apenas $02 \%$ são pais (desempregados). Não encontramos nenhum tio ou avô como acompanhantes.

Aos termos acesso a esses dados, percebemos claramente que as mulheresmães assumem como sendo "apenas sua" a obrigação de cuidar do/a filho/a com deficiência.

A maternidade, na atualidade, especificamente no interior nordestino, constitui-se, uma violência simbólica, podendo-se dizer que tal violência é ainda maior se essa mulher é mãe de uma pessoa com deficiência.

Quando indagamos sobre o motivo dos pais não realizarem a tarefa do cuidado no acompanhamento dos/as filhos/as, a maioria das mães apresentam defensiva de seus companheiros como é o caso da mulher-mãe Cumaru (30 anos) que argumenta; "Ele já me ajuda demais, nem todo homem faz o que ele faz, trazendo o mantimento para dentro de casa”.

Neste sentido, a mulher legitima um valor já arraigado na mente masculina "o homem se vê como universal (homo). Ele se considera o representante mais perfeito da humanidade, o critério de referência”. (BADINTER, 1993, p. 7)

Notamos na fala da mulher-mãe Cumaru a internalização de valores onde não se questiona o papel da mulher como cuidadora. A mulher-mãe não se percebe como vítima de violência simbólica (BORDIEU, 2003), à medida que assume, individualmente, uma tarefa que deveria ser compartilhada.

A mulher-mãe Macieira (35 anos) mostra-se insatisfeita com a omissão do pai de seu filho dizendo: "Ele não faz nada, tudo sou eu", representando sua indignação o caráter minoritário, pois esse tipo de comportamento não foi questionado pela maioria das mulheres-mães. Observamos, na sua fala, uma rejeição ao comportamento do seu companheiro, modo de agir, que não reflete os valores da nossa sociedade que isenta o homem do cuidado dos/das filho/a/s.

A mulher-mãe Umburana (32 anos) diz que é parecida com essa árvore por ter uma raiz forte. Ela é casada e tem três filhos sendo um deles deficiente (Paralisia Cerebral). Segundo ela, a criança passou da hora de nascer, por isso faltou oxigênio no cérebro provocando a deficiência. Semelhantemente as demais, cuida do filho sozinha. 
A mulher-mãe Bananeira (41 anos) tem apenas uma filha de cinco meses que tem Síndrome de Down, (que não foi aceita pela mãe ao nascer). Ela relata que entrou em desespero ao saber que a menina era uma criança diferente das demais e chegou a perguntar ao médico se a filha havia sido trocada. Bananeira afirma que o pai da menina não a ajuda no cuidado com a filha e nos diz: "ele não sabe fritar nem ovo, e acrescenta: já briguei muito com ele por causa disso, hoje já nem peço para ele ajudar, pois ele sempre diz que cozinha é coisa de mulher".

O companheiro da mãe Bananeira é extremamente sexista com relação ao tratamento com sua esposa, sendo esse comportamento fruto dessa construção cultural que é naturalizada pela nossa sociedade.

As mulheres em sua maioria afirmaram que seria impossível o parceiro ajudar, pois já chegava bastante cansado do trabalho. Para elas (as mães), a obrigação de cuidar dos filhos/as deve ser da mãe, pois elas, é que, ficam em casa e não trabalham tanto quanto o parceiro. Tal fato mostra a condição inferior do trabalho reprodutivo.

Constatamos um grande número de mães separadas e questionamos as mesmas sobre o motivo da separação. Indagamos se elas supunham que a separação tinha alguma ligação ao fato do/a filho/a ser uma pessoa com deficiência.

Algumas negaram que os fatos tenham relação, mas percebemos que em alguns casos as mulheres-mães têm dúvida, mesmo respondendo que não, pois quando respondiam ficavam pensativas, talvez porque nunca tinham refletido sobre tal possibilidade e ao serem questionadas foram obrigadas a cogitar tal motivação para seus ex-parceiros.

Notamos que a maioria das mães, separadas dos parceiros, sentem-se aliviadas por terem eles longe do seu convívio. Uma minoria revelou angústia e demonstrou tristeza por ter sido abandonada pelo companheiro, não ter ajuda financeira, como é o caso da mulher-mãe Quixabeira (18 anos) que diz:

Engravidei com 13 anos, o meu namorado quando soube que eu estava grávida me deixou e foi embora para outra cidade, eu não sabia o que fazer e só fazia chorar. Quando contei para minha mãe ela me chamou de tudo o que não presta, meu pai e meus irmãos pararam de falar comigo, foi um inferno. Até hoje minha mãe passa na minha cara. (QUIXABEIRA, 2008). 
A filha de Quixabeira tem 04 anos e tem Paralisia Cerebral. Comprometeu a fala e os movimentos. Notamos que a mãe tem muito carinho pela filha, mas se sente culpada pelo fato dela ser deficiente, além de amargar a tristeza de não ter o pai de sua filha ao seu lado. Ela disse ser triste por sua mãe não permitir que ela estude, e não a ajuda nos cuidados com sua filha.

Percebemos que, no cenário da atualidade, o destaque para instabilidade de lugares sociais tem se tornado lugar comum: o casamento tardio, a gravidez precoce, a "barriga de aluguel", o crescimento do divórcio, a paternidade ausente, a chefia feminina dos lares, a luta de homens contra o aborto (pelo direito ao filho que a mulher não quer ter) e, ao contrário, pelo direito de não assumir uma paternidade.

Na contramão da história, visualizamos a maternidade solitária, a sobrecarga de atividades exercidas pelas mulheres-mães em detrimento aos pais que, na maioria das vezes, são omissos com relação ao cuidado cotidiano dos/as filhos/as com deficiências.

Por fim, os resultados da pesquisa confirmam a necessidade de propiciar uma prática diferenciada com relação à problemática das relações de gênero no cotidiano das famílias das pessoas com deficiência, articulando debates sobre o exercício da maternidade e paternidade responsável.

Ao buscar entender os modelos de maternidade e paternidade, buscamos também compreender como as pessoas fazem suas escolhas e como se dão as relações de poder entre homens e mulheres, revelando uma visão relacional de gênero onde as relações entre os sexos são construídas como base na interação social.

Não podemos esquecer que tanto mulheres quanto homens exercem inúmeros papéis em sua vida cotidiana, participam da dinâmica social das mais diversas formas e não se comportam da mesma maneira o tempo todo. Portanto os papéis da maternidade e paternidade são moldados por escolhas individuais e por pressões situacionais.

Assim, esperamos provocar um olhar acadêmico-científico sobre as raízes da desigualdade justificada e alicerçada nas práticas sociais da maternidade e paternidade de pessoas com deficiências, que reiteram a iniquidade de gênero, através das diferenças entre as responsabilidades diferenciadas por sexo. 


\section{Referências}

ARIÉS, P. História social da criança e da família. Rio de Janeiro: LTC, 1981.

BADINTER, E.. XY Sobre a identidade masculina. 2 ed. Rio de Janeiro: Editora Nova Fronteira, 1993.

BEAUVOIR, S. O segundo sexo. Rio de Janeiro: Nova Fronteira, 1980.

BOURDIEU, P. A dominação Masculina. Tradução de Maria Helena Kühner. Rio de Janeiro: Bertrand Brasil, 2003.

CHODOROW, N. Psicanálise da maternidade: uma crítica a Freud a partir da mulher. Rio de Janeiro: Rosa dos Tempos, 1990.

CONNEL, R. W. Políticas da masculinidade. Educação e Realidade, n. 20. jul./dez, 1995. p.185-206.

FORNA, A. Mãe de todos os mitos: como a sociedade modela e reprime as mães. Rio de Janeiro: Ediouro, 1999.

LO BIANCO, A. C. A Psicologização do Feto. In: FIGUEIRA, S. (Org.) A cultura da psicanálise. São Paulo: Brasiliense, 1985, p. 94-115.

SCOTT, J. Gênero: uma categoria útil para a análise histórica. Educação \& realidade. Porto Alegre, v.20, n.2. jul/dez, 1995. p. 71-99.

VAINFAS, R. Os protagonistas anônimos da história: micro-história. Rio de Janeiro: Editora Campus, 2002. 